\title{
COMPARISON BETWEEN THE REACTIVITY OF COAL AND SYNTHETIC COAL MODELS
}

\author{
A. Arenillas, C. Pevida, F. Rubiera and J.J. Pis* \\ Instituto Nacional del Carbón, CSIC. Apartado 73. 33080 Oviedo, Spain
}

\begin{abstract}
A mixture of carbon compounds was pyrolysed under an inert atmosphere at different temperatures in a fixed bed reactor. The resultant chars were characterised in terms of texture and thermal behaviour. Textural characterisation of the chars was carried out by $\mathrm{N}_{2}$ and $\mathrm{CO}_{2}$ adsorption isotherms at $-196{ }^{\circ} \mathrm{C}$ and $0{ }^{\circ} \mathrm{C}$, respectively. Char isothermal reactivity in air at $500{ }^{\circ} \mathrm{C}$, and in $\mathrm{CO}_{2}$ at $1000{ }^{\circ} \mathrm{C}$, was performed in a thermogravimetric analyser (TGA). Temperature-programmed combustion tests under $20 \%$ oxygen in argon were also performed in the TGA linked to a mass spectrometer (TGA/MS). The results showed that char textural properties do not always relate well to their reactivity. Not only do physical properties (e.g. surface area, porosity) but also chemical properties (e.g. active sites concentration and distribution) play an important role in the reaction of carbonaceous material and oxidant. On the other hand, in terms of chemical composition the chars obtained from the mixture of carbon compounds were very similar to the chars produced under the same experimental conditions by a high volatile bituminous coal. The fact that carbon compounds are well known makes it easier to obtain knowledge about the functional groups present in synthetic char, and to study the mechanisms of heterogeneous reactions such as the reduction of NO with carbon.
\end{abstract}


Keywords: coal char reactivity, textural properties, model compounds

\section{Introduction}

The increased use of coal processing to produce alternative fuels or to reduce pollutant emissions has made it imperative to obtain a better understanding of the reaction mechanisms involved. First, however, it is essential to know the surface chemistry of carbon materials in order to be able to establish a valid method for the study of these mechanisms.

The chemical and physical structure of coal is extremely complex and heterogeneous, and consists of a highly cross-linked network. Single model compounds have been used in order to provide additional insights into the complex processes that occur in the pyrolysis of coal [1-2]. However, although interesting results have been obtained in this way, the picture is an over simplified one and leaves out important aspects such as coal structure, interactions between different surface groups and cross-linking reactions. In order to study the evolution of nitrogen during coal pyrolysis or combustion, single model compounds containing nitrogen or special surface treatments like ammoxidation (v.g. treatment with ammonia) are widely used. However, for the study of the mechanisms of reaction, nitrogen must be distributed throughout the bulk of the coal and not just on the surface. In addition, the nitrogen functionalities in the sample must be known.

On the other hand, the heterogeneous reduction of nitrogen oxides by reaction with coal char are still not completely understood and given the complexity of coal char, the use 
of model compounds may facilitate a better understanding of the pathways involved in these reactions.

The results presented in this work are part of a study on heterogeneous reduction mechanisms of nitrogen oxides. A mixture of model compounds including nitrogen functionalities commonly present in coal was used to obtain a synthetic coal. The absence of mineral matter in the mixture avoids possible catalytic effects, which are undesirable when trying to isolate the effect of carbon active surface groups. In addition, characterisation of a series of chars from a bituminous coal and from the mixture of model carbon compounds was carried out in terms of chemical composition, texture and thermal behaviour.

\section{Method}

A series of model compounds were selected and mixed in order to obtain a synthetic coal with a well known structure and composition. Phenol-formaldehyde resin (PFR) was used as carbonaceous matrix. This was mixed with 3,4,9,10-perylenetetracarboxylic dianhydride $\quad\left[\mathrm{C}_{24} \mathrm{H}_{8} \mathrm{O}_{6}\right], \quad \mathrm{PTC}$, and N-containing model compounds. Poly-4-vinylpyridine $\left[\left(\mathrm{C}_{7} \mathrm{H}_{7} \mathrm{~N}\right)_{\mathrm{x}}\right], \mathrm{p} 4 \mathrm{VP}$, was used as the pyridinic source and polyvinylpyrrolidone $\left[\left(\mathrm{C}_{6} \mathrm{H}_{9} \mathrm{NO}\right)_{\mathrm{x}}\right], \mathrm{PVP}$, as the pyrrolic source. In order to create linkages between the individual model compounds as in a real coal, a curing step for the mixture was performed under Ar flow at $5{ }^{\circ} \mathrm{C} \min ^{-1}$ from room temperature up to an optimised temperature of $425^{\circ} \mathrm{C}$ [3]. The final cured mixture was denoted as synthetic coal, SC. It needs to be pointed out that it was not the aim of this work to simulate the behaviour of a particular coal, but to obtain a material with a known composition and 
structure that would be representative of a real coal. For this purpose a high volatile bituminous coal, CA, was used as a reference.

The SC and CA samples were pyrolysed in a horizontal quartz reactor (i.d. $30 \mathrm{~mm}$ ) under He flow at $15{ }^{\circ} \mathrm{C} \min ^{-1}$ up to different temperatures $\left(600\right.$ and $\left.850{ }^{\circ} \mathrm{C}\right)$. The chars obtained were denoted as SC-600, SC-850, CA-600 and CA-850, respectively.

Temperature-programmed combustion (TPC) tests of the raw materials, SC and CA, were carried out in a thermogravimetric analyser, TGA. In these experiments the temperature was raised at $15{ }^{\circ} \mathrm{C} \min ^{-1}$ up to $1000{ }^{\circ} \mathrm{C}$, under $50 \mathrm{~mL} \mathrm{~min}^{-1}$ of $20 \%$ oxygen in argon. The TGA was linked to a mass spectrometer for on-line gas analysis (TGA/MS). The optimisation of the coupling system and the normalisation procedure of the MS profiles in order to perform a semi-quantitative analysis of the gaseous compounds evolved are described elsewhere [4].

Isothermal $\left(500{ }^{\circ} \mathrm{C}\right)$ reactivity tests under air were also performed in the TGA for the chars studied (SC-600, SC-850, CA-600 and CA-850). A previous cleaning step under Ar flow $\left(50 \mathrm{~mL} \mathrm{~min}{ }^{-1}\right.$ ) was conducted by heating the sample at $15^{\circ} \mathrm{C} \mathrm{min}^{-1}$ up to $850{ }^{\circ} \mathrm{C}$. In addition, isothermal $\left(1000^{\circ} \mathrm{C}\right)$ reactivity tests under $50 \mathrm{~mL} \mathrm{~min}^{-1}$ of $\mathrm{CO}_{2}$ were performed.

The texture of these chars was characterised by $\mathrm{N}_{2}$ and $\mathrm{CO}_{2}$ adsorption isotherms at $-196{ }^{\circ} \mathrm{C}$ and $0{ }^{\circ} \mathrm{C}$, respectively. From the $\mathrm{N}_{2}$ adsorption isotherms, the apparent surface areas of the samples were obtained by using the BET equation [5]. The Dubinin- 
Radushkevich (DR) method was applied to the $\mathrm{CO}_{2}$ adsorption isotherms in order to obtain the corresponding micropore volumes and surface areas of the chars studied [6].

The active surface area, ASA, was also evaluated by using the TGA/MS system. This involved cleaning the surface of the samples by heating in a stream of dry argon at $15^{\circ} \mathrm{C} \min ^{-1}$ up to $1000^{\circ} \mathrm{C}$, the sample being maintained at this final temperature for 5 hours. Subsequently, the temperature was lowered to a previously optimised temperature of $250^{\circ} \mathrm{C}$. After the chemisorption step, the oxygen was swept by flowing Ar, and a temperature-programmed desorption (TPD) was performed in the TGA by heating the sample at $15^{\circ} \mathrm{C} \mathrm{min}^{-1}$ from room temperature to $1000{ }^{\circ} \mathrm{C}$. The desorbed gases $\left(\mathrm{CO}\right.$ and $\left.\mathrm{CO}_{2}\right)$ were followed by means of a mass spectrometer (MS), and they were correlated to the amount of chemisorbed oxygen, after calibration with calcium oxalate [7]. In this way the amount of active sites in the samples was evaluated.

The XRD patterns of the chars were obtained for their structural characterisation. A Siemens D5000 diffractometer was used to record X-ray intensities scattered by char samples, using $\mathrm{Cu} \mathrm{K}$ radiation $(\lambda=0.15406 \mathrm{~nm})$ at a step size of $0.01^{\circ}$ over the angular $2 \theta$ range of $5-54^{\circ}$.

\section{Results and Discussion}

The proximate and ultimate analyses of SC and CA are shown in Table 1. A striking similarity between both samples can be observed. The main differences are the absence of ash and sulphur in SC, as no mineral matter or sulphur compounds were included in its composition. Both samples were thoroughly characterised [3] (i.e., chemical 
analyses, FT-IR, temperature-programmed desorption tests, XPS) and the results showed that, at least chemically, SC resembles a real coal quite well.

The mass loss profiles and the DTG curves of SC and CA during the combustion tests are presented in Figure 1. Two characteristic temperatures were used to define the combustion behaviour of the samples: Tv or the volatile matter initiation temperature (calculated as the temperature at which the rate of mass loss is $0.005 \% \mathrm{~s}^{-1}$ after the loss of moisture and oxygen chemisorption), and the burnout temperature, $\mathrm{Tb}$ (calculated as the temperature at which the value of the mass loss after the maximum of the DTG curve is $\left.0.005 \% \mathrm{~s}^{-1}\right)$. Both samples, SC and CA, present the same Tv value $\left(317^{\circ} \mathrm{C}\right)$. However, SC presents a $\mathrm{Tb}$ value which is lower than that of $\mathrm{CA}\left(565\right.$ and $584{ }^{\circ} \mathrm{C}$ for SC and CA, respectively). Furthermore, the slope of the mass loss profile, besides the height of the DTG peak in Figure 1 indicates that although both samples exhibit similarities, $\mathrm{SC}$ is more reactive than $\mathrm{CA}$.

Figure 2 shows the evolution profiles of different gaseous compounds during the TPC tests. It can be observed that SC resembles the composition and functionalities of a real coal quite well as inferred from a comparison between the emission of different compounds in both samples, SC and coal CA. It should also be noted that the similarities in peak shape and temperature were found both in the major compounds (i.e., $\mathrm{CO}, \mathrm{CO}_{2}$ or $\mathrm{H}_{2} \mathrm{O}$ ) and in the minor compounds (see $\mathrm{NO}$ evolution in Figure 1). This is of utmost importance and confirms the usefulness of using the synthetic coal and its chars for the study of the heterogeneous formation/reduction reactions of nitrogen oxides. 
The proximate and ultimate analyses of the chars obtained after the curing step of SC and $\mathrm{CA}$ at 600 and $850^{\circ} \mathrm{C}$ are given in Table 1 . There is a decrease in the volatile matter content, hydrogen and oxygen as the devolatilisation temperature of SC and CA increases. The SC and CA chars series also show a striking similarity in composition.

The conversion of the chars (burn-off) during the isothermal reactivity experiments at $500{ }^{\circ} \mathrm{C}$ under air is displayed in Figure 3. It can be observed that in the early stages of the reaction (up to $250 \mathrm{~s}$ ) the four chars are divided into two groups according to the heat treatment they underwent. Thus the samples obtained at $600{ }^{\circ} \mathrm{C}$ present the same burn-off evolution, but their reactivity is higher than that of the samples obtained at $850^{\circ} \mathrm{C}$. As the reaction with oxygen proceeds, the properties of the samples (i.e., morphology, texture and active sites) take on more relevance. Thus, the SC chars are more reactive than the chars from coal CA, as was already observed in the TPC tests. However, in both series the chars obtained at lower temperatures $\left(600^{\circ} \mathrm{C}\right)$ are more reactive than those obtained at higher temperatures $\left(850^{\circ} \mathrm{C}\right)$. As diffusion of the gaseous compounds throughout the solid sample depends a lot on textural characteristics, char reactivity is usually related to surface areas measured by physical adsorption. The $\mathrm{N}_{2}$ adsorption isotherms at $-196^{\circ} \mathrm{C}$ are presented in Figure 4. Almost all the $\mathrm{N}_{2}$ is adsorbed by the chars at low relative pressures (type $\mathrm{I}$ in the BDDT classification [8]), indicating that they are microporous solids. The chars from SC adsorb more $\mathrm{N}_{2}$ and thus they present higher BET surface areas (see Table 2) than the corresponding CA chars. This may be related to the higher reactivity of the SC series mentioned above. However, the chars obtained at higher temperatures $\left(850^{\circ} \mathrm{C}\right)$ are less reactive, as can be seen in the conversion profiles of Figure 3, although they present higher surface areas. 
The isothermal reactivity tests under $\mathrm{CO}_{2}$ at $1000^{\circ} \mathrm{C}$ allow to complete the study on the effect of texture on reactivity, as the $\mathrm{CO}_{2}$ is less reactive than oxygen. Figure 5 shows the results obtained. The synthetic chars are more reactive than the coal chars, and no significant differences were observed between chars obtained at different temperatures. On the other hand, the $\mathrm{CO}_{2}$ adsorption isotherms performed at $0{ }^{\circ} \mathrm{C}$ are presented in Figure 6. The chars from SC show greater adsorption and thus a higher micropore volume, $\mathrm{W}_{0}$, and surface area with the $\mathrm{DR}$ method, $\mathrm{S}_{\mathrm{DR}}$ (cf. Table 2). It should be pointed out that the surface areas measured by $\mathrm{CO}_{2}$ adsorption are much higher than those measured by $\mathrm{N}_{2}$ adsorption which is indicative of the presence of narrow micropores [9]. Nevertheless, the differences in $\mathrm{CO}_{2}$ surface area values between chars obtained from the same material but at different temperatures are negligible.

Several parameters have been used to express char reactivity. Here the reactivity at $50 \%$ of burn-off, $\mathrm{R}_{50}$, has been selected as the characteristic parameter for both reactivity tests, under air and $\mathrm{CO}_{2}$. Figure 7 a shows the relationship between $\mathrm{R}_{50}$ in air and the BET surface areas, no relationship being found as mentioned before. However, there is a clear linear relationship between $\mathrm{R}_{50}$ in $\mathrm{CO}_{2}$ and the $\mathrm{DR}$ surface area from $\mathrm{CO}_{2}$ adsorption isotherms (see Figure 7b).

Therefore, the relationship between reactivity and textural properties (i.e., surface area) is not a general rule, and surface area values cannot be used directly as an indicator of reactive properties or as a parameter to predict reactivity. The fundamental components of carbon reactivity are known to be (i) surface area, (ii) surface accessibility, (iii) carbon active sites (edges, basal plane defects, heteroatoms), and (iv) catalytic active 
sites created by natural inorganic impurities or dopents [10]. According to the results obtained in this work, the first two components do not relate well to the reactivity of the samples. On the other hand, the catalytic effects have no influence at all on the SC samples as no mineral matter is included. The determining factor, therefore, must be the carbon structure and the concentration and distribution of active sites.

The XRD patterns of the chars studied were analysed in order to obtain their structural parameters. The conventional Scherrer equations were used in order to determine the lateral size of the crystallite, $L a$, the stacking height of the crystallite, $L c$, and the distance between two graphene layers, $d_{002}$. The values of these crystallographic parameters are presented in Table 3 . It can be observed that the $d_{002}$ values are nearly the same for all the chars. The main differences were found in the crystallite parameters, La and Lc. Although chemically SC resembles a high volatile bituminous coal quite well, it must be pointed out that the lamellae and the degree of order of these lamellae are determined by the initial nature of the coal and the extent of cross-linking [11]. Thus, differences in crystallite size were to be expected. Special attention was paid to the La parameter which is related to the hexagonal ring structure in the char crystallites. Table 3 shows that CA chars present higher values than SC chars. Furthermore, in both cases $L a$ values increase with the temperature of the treatment. This is related with the condensation degree of the samples: the higher the La value, the higher the condensation degree. This effect is reflected by a decrease in the ratio of edge (more reactive) to basal carbon atoms due to the increase in the diameter of the crystallite [12]. As a consequence, the reactivity of the samples under air diminishes, when $L a$ increases due to there being a lower number of active carbon sites. Figure $8 \mathrm{a}$ shows the relationship between $L a$ and the reactivity parameter $\mathrm{R}_{50}$ in air, which is clearly linear. 
Thus, it can be said that according to the results obtained in this work the reactivity correlated very well with domain growth.

Another parameter associated with the concentration of active sites is the active surface area, ASA. This parameter represents the surface area covered only by the active sites and it usually relates better to reactivity than the surface areas from physical adsorption. In Figure $8 \mathrm{~b}$ the ASA values obtained for the chars were represented versus the reactivity parameter $\mathrm{R}_{50}$ in air. As can be seen, a linear relationship was also observed, i.e., as the ASA value increased, the reactivity of the char also increased.

Although the surface areas obtained from physical adsorption do not always correlate well with the reactivity of the samples and other parameters seem to be better options, both methods (XRD and ASA determination) lend themselves to controversy. Carbonaceous materials treated at low or moderate temperatures $\left(<1800^{\circ} \mathrm{C}\right)$ are generally very disordered, and the conventional methods for XRD analysis have many limitations [13]. On the other hand, the determination of ASA depends very much on the method used [7]. For this reason a direct comparison of the ASA values provided by different research groups cannot be undertaken.

\section{Conclusions}

The results presented in this work show that a synthetic coal, obtained by curing a mixture of model compounds, presents many similarities with a bituminous coal at least chemically (i.e., chemical analyses of raw materials and their chars, gas evolution profiles during combustion). However, there are some differences in the reactivity 
behaviour of the synthetic and real coals, either in air at $500{ }^{\circ} \mathrm{C}$ or in $\mathrm{CO}_{2}$ at $1000{ }^{\circ} \mathrm{C}$. The reactivity parameters do not correlate well with the textural properties of the samples. Thus, the latter cannot be used as an indicator of reactive properties, as a general rule. It was also found for the samples used in this work, that not only physical properties (e.g. surface area, porosity) but also chemical properties (e.g. active sites concentration and distribution) do play an important role in the reactivity behaviour of carbonaceous materials versus oxygen or $\mathrm{CO}_{2}$. 


\section{References}

[1] J.R. Pels, F. Kapteijn, J.A. Moulijn, Q. Zhu, K.M. Thomas, Carbon 33, 11 (1995) 1641.

[2] S. Murata, M. Nakamura, M. Miura, M. Nomura, Energy \& Fuels 9 (1995) 849.

[3] A. Arenillas, C. Pevida, F. Rubiera, J.J. Pis, 15th Int. Symp. Anal. Appl. Pyrol., Leoben, (2002) 49.

[4] A. Arenillas, F. Rubiera, J.J. Pis, J. Anal. Appl. Pyrol. 50 (1999) 31.

[5] J.B. Parra, J.C. de Sousa, R.C. Bansal, J.J. Pis, J.A. Pajares, Adsorption Sci. Technol. 12 (1995) 51.

[6] J.F. Byrne, H. Marsh, in J.W. Patrick, Ed., Porosity in carbons: Characterisation and applications. Edward Arnold (1995).

[7] A. Arenillas, F. Rubiera, J.B. Parra, J.J. Pis, Carbon 40 (2002) 1381.

[8] S. Brunauer, L.S. Deming, W.E. Deming, E.J. Teller, Am. Chem. Soc. 62 (1940) 1723.

[9] J.J. Pis, M. Mahamud, J.B. Parra, J.A. Pajares, R.C. Bansal, Fuel Proc. Technol. 50 (1997) 249. 
[10] R.H. Hurt, 27 $7^{\text {th }}$ Symp. (Int.) on Comb./The Comb. Institute (1998) 2887.

[11] M.L. Chan, J.M. Jones, M. Pourkashanian, A. Williams, Fuel 78 (1999) 1539.

[12] O. Senneca, P. Russo, P. Salatino, S. Masi, Carbon 35, 1 (1997) 141.

[13] B. Feng, S.K. Bhatia, J.C. Barry, Carbon 40 (2002) 481. 
Table 1. Proximate and ultimate analyses of the coals and their chars

\begin{tabular}{|c|c|c|c|c|c|c|c|}
\hline \multirow{2}{*}{ Sample } & \multicolumn{2}{|c|}{ Proximate Analysis (\% $\left.\% \mathrm{t}, \mathrm{db}^{\mathrm{a}}\right)$} & \multicolumn{5}{|c|}{ Ultimate Analysis ( $\% \mathrm{wt}, \mathrm{daf}^{\mathrm{b}}$ ) } \\
\hline & $\mathrm{VM}$ & Ash & $\mathrm{C}$ & $\mathrm{H}$ & $\mathrm{N}$ & $\mathrm{S}$ & $\mathrm{O}$ \\
\hline $\mathrm{SC}$ & 39.2 & 0.0 & 81.8 & 5.4 & 2.6 & 0.0 & 10.2 \\
\hline $\mathrm{CA}$ & 37.7 & 7.6 & 84.4 & 5.5 & 1.8 & 1.6 & 6.7 \\
\hline SC -600 & 19.1 & 0.0 & 89.7 & 2.4 & 2.2 & 0.0 & 5.7 \\
\hline SC -850 & 11.3 & 0.0 & 95.5 & 1.2 & 1.6 & 0.0 & 1.7 \\
\hline CA - 600 & 16.2 & 11.3 & 89.3 & 2.6 & 2.2 & 1.6 & 4.3 \\
\hline $\mathrm{CA}-850$ & 7.9 & 14.2 & 93.1 & 1.3 & 2.0 & 2.1 & 1.5 \\
\hline
\end{tabular}

${ }^{\mathrm{a}}$ dry basis; ${ }^{\mathrm{b}}$ dry ash free basis 
Table 2. Textural properties from $\mathrm{N}_{2}$ and $\mathrm{CO}_{2}$ adsorption of the chars studied

\begin{tabular}{ccccc}
\hline \multirow{2}{*}{ Sample } & \multicolumn{2}{c}{$\mathrm{N}_{2}$ Adsorption } & & \multicolumn{2}{c}{$\mathrm{CO}_{2}$ Adsorption } \\
\cline { 2 - 3 } $\mathrm{SC}-600$ & BET Area $\left(\mathrm{m}^{2} \mathrm{~g}^{-1}\right)$ & & $\mathrm{W}_{0}\left(\mathrm{~mm}^{3} \mathrm{~g}^{-1}\right)$ & $\mathrm{S}_{\mathrm{DR}}\left(\mathrm{m}^{2} \mathrm{~g}^{-1}\right)$ \\
\hline $\mathrm{SC}-850$ & 36 & 116 & 305 \\
$\mathrm{CA}-600$ & 87 & 123 & 322 \\
$\mathrm{CA}-850$ & 9 & 87 & 227 \\
\hline
\end{tabular}


Table 3. Crystallographic parameters from X-ray diffraction of the chars studied

\begin{tabular}{cccc}
\hline Sample & $\mathrm{d}_{002}(\mathrm{~nm})$ & Lc $(\mathrm{nm})$ & La (nm) \\
\hline SC - 600 & 0.41 & 13.9 & 4.5 \\
SC - 850 & 0.41 & 25.1 & 6.9 \\
CA - 600 & 0.37 & 1.2 & 6.2 \\
CA - 850 & 0.37 & 1.1 & 9.9 \\
\hline
\end{tabular}



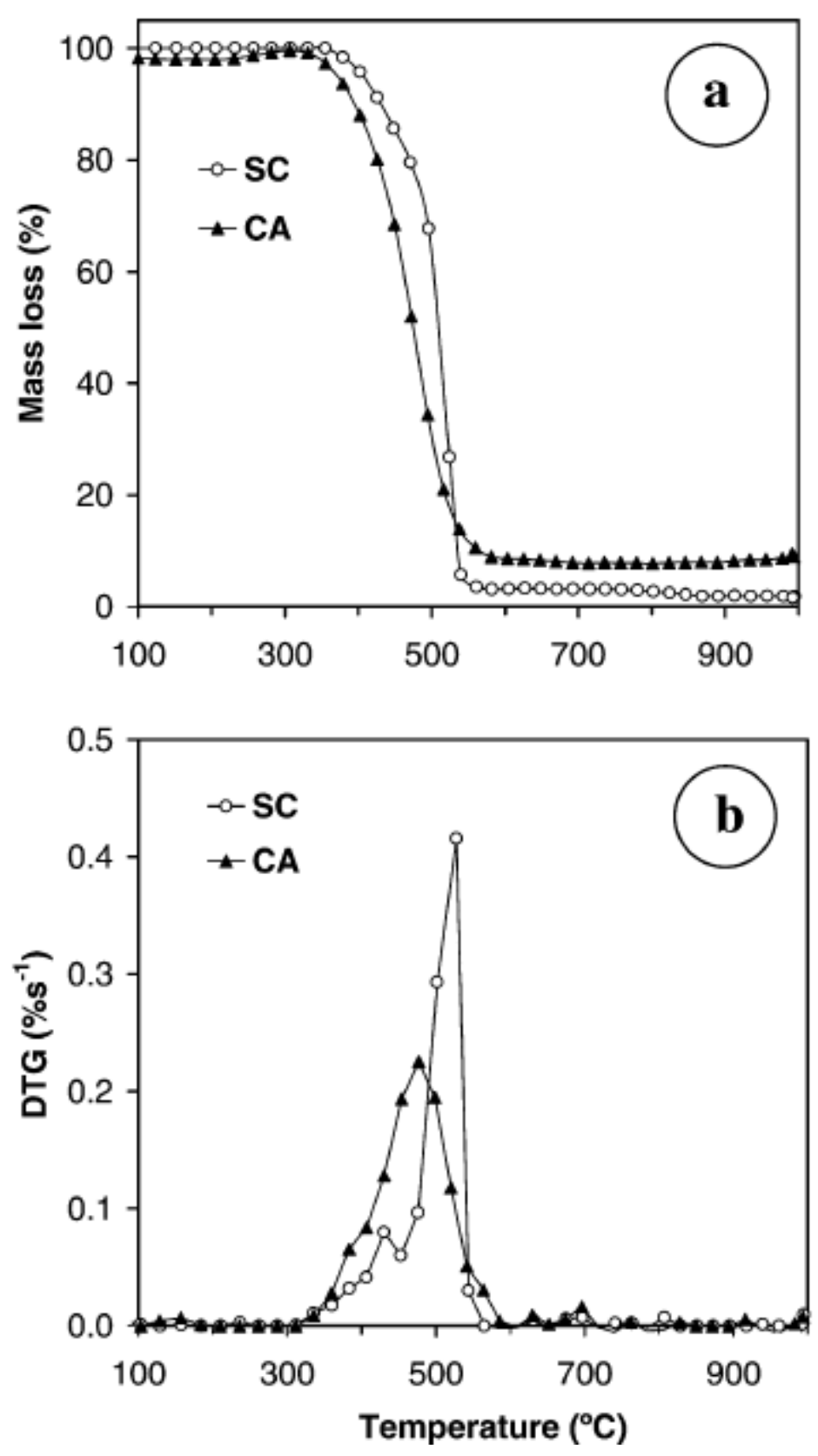

Figure 1. Mass loss profiles (a) and DTG curves (b) obtained during the temperatureprogrammed combustion tests of the synthetic coal (SC) and a bituminous coal (CA). 

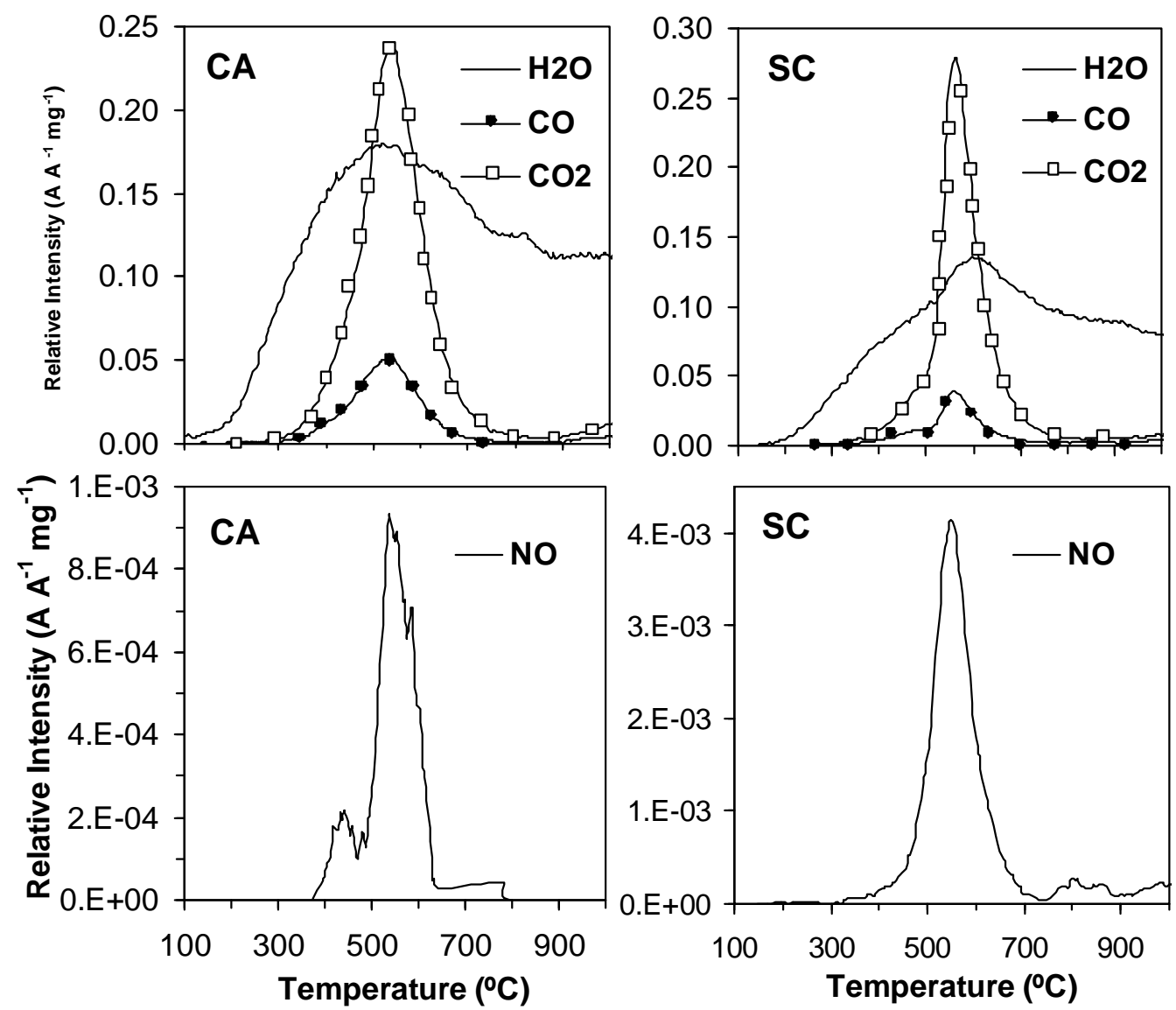

Figure 2. Evolution of gaseous compounds during the temperature-programmed combustion tests of the synthetic coal (SC) and a bituminous coal (CA). 


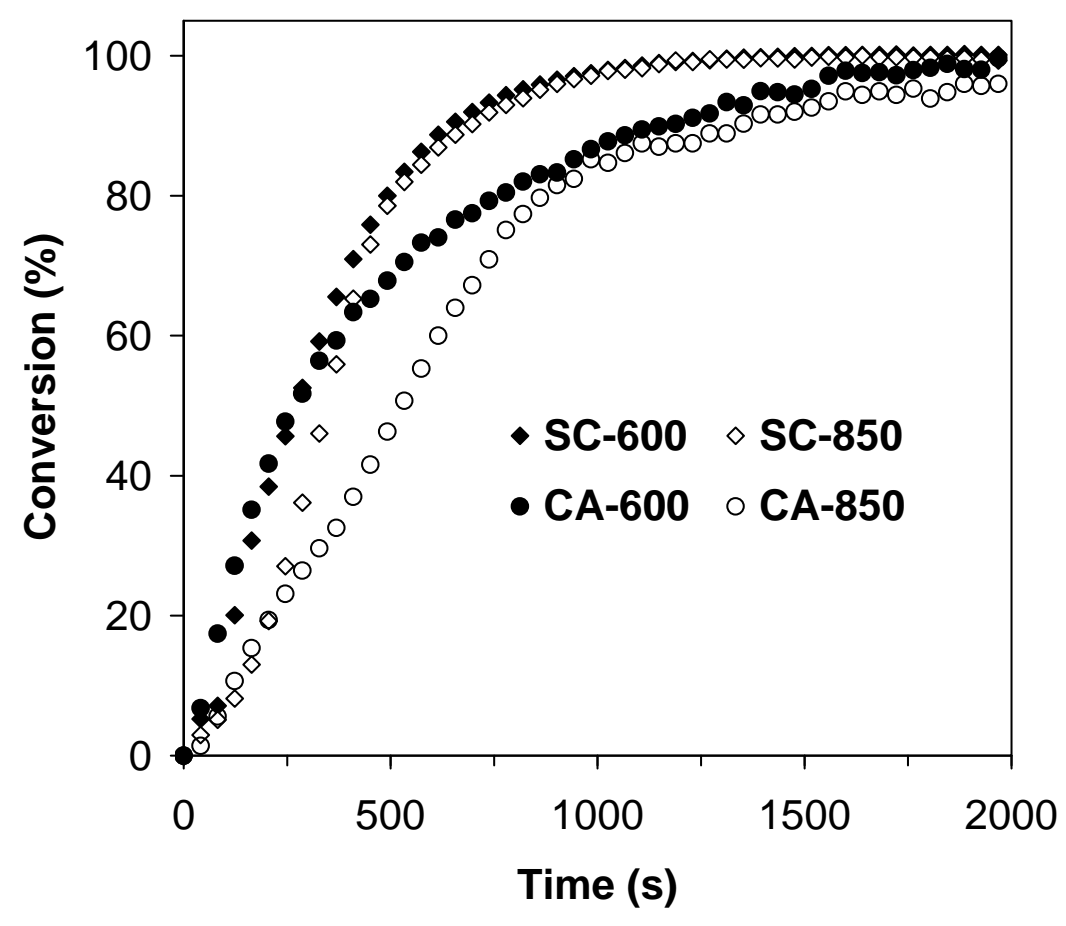

Figure 3. Variation in char conversion with time during isothermal reactivity tests at $500{ }^{\circ} \mathrm{C}$ in air. 


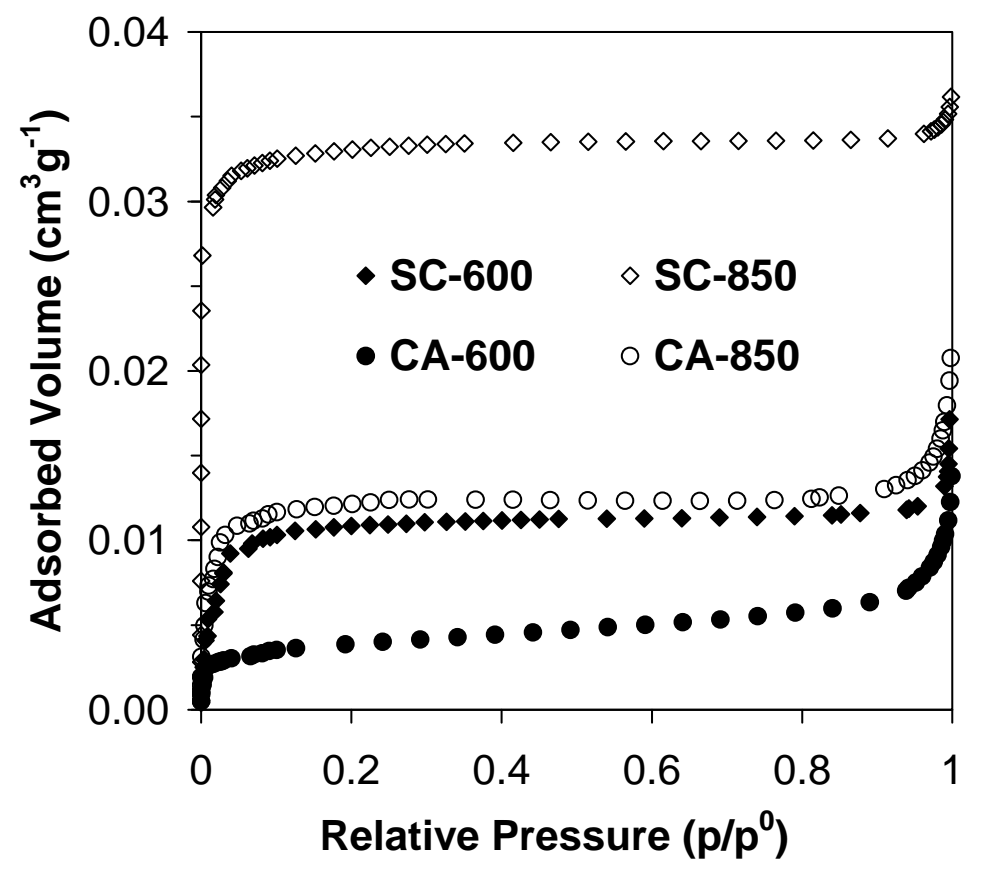

Figure $4 . \mathrm{N}_{2}$ adsorption isotherms at $-196^{\circ} \mathrm{C}$ for the chars studied. 


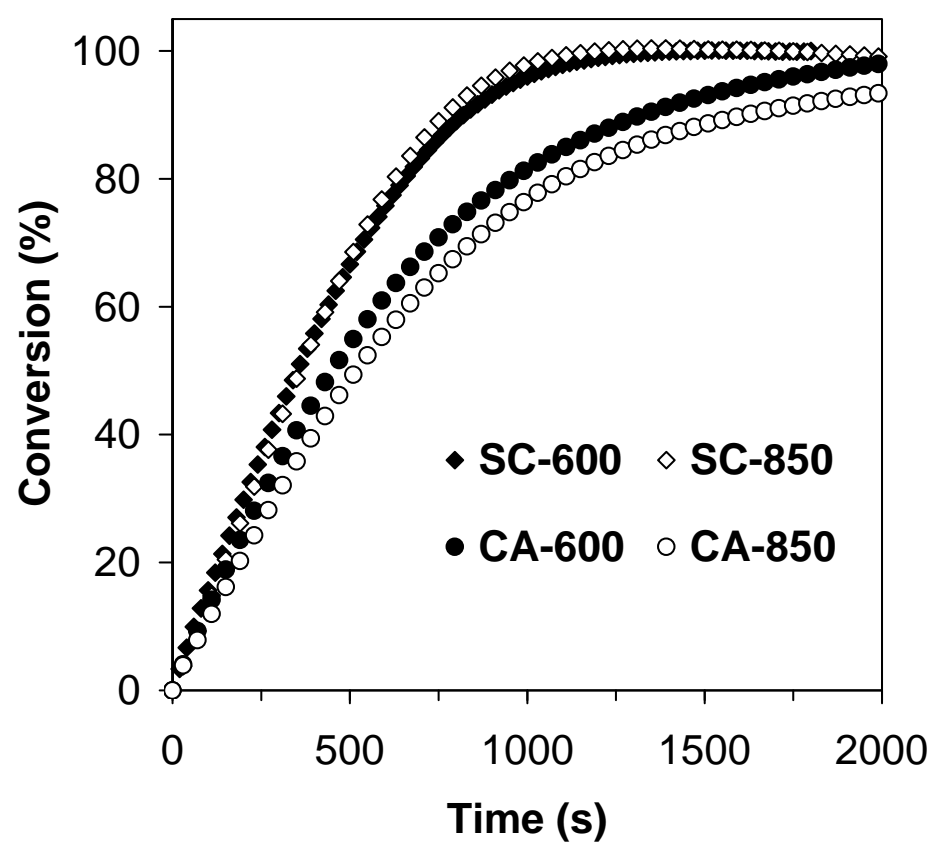

Figure 5. Variation in char conversion with time during isothermal reactivity tests at $1000{ }^{\circ} \mathrm{C}$ in $\mathrm{CO}_{2}$. 


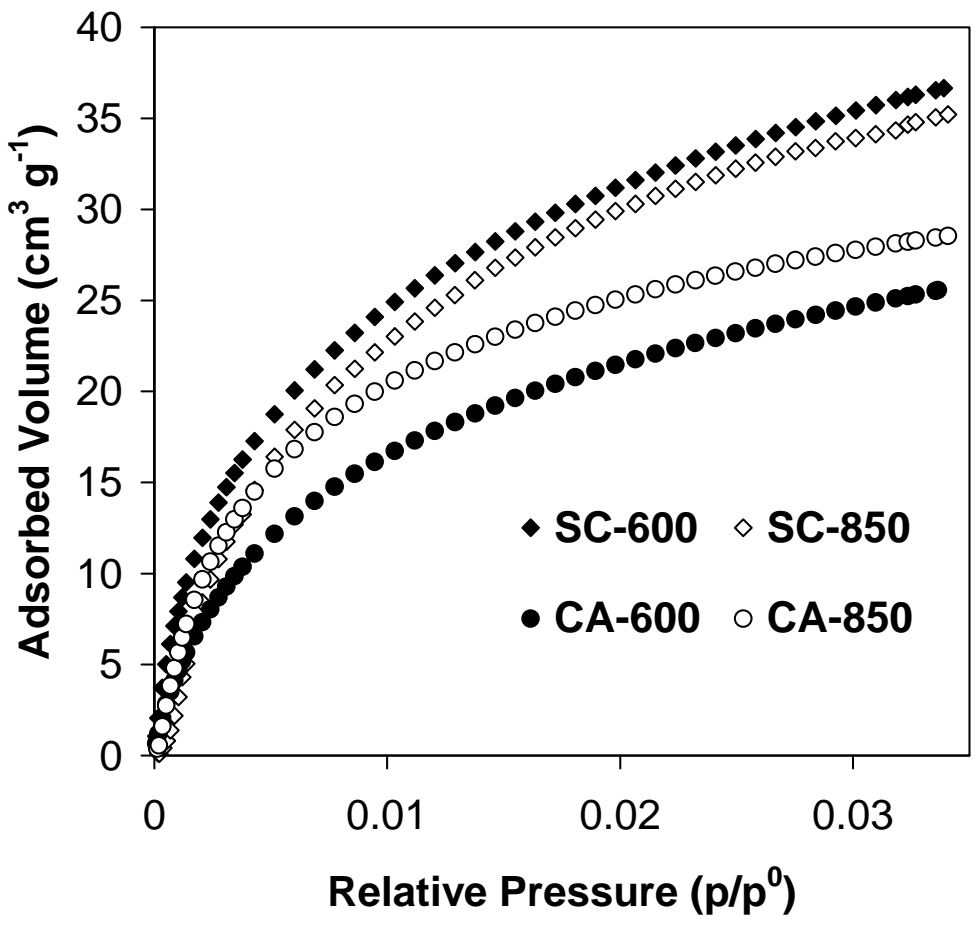

Figure 6. $\mathrm{CO}_{2}$ adsorption isotherms at $0{ }^{\circ} \mathrm{C}$ for the chars studied 

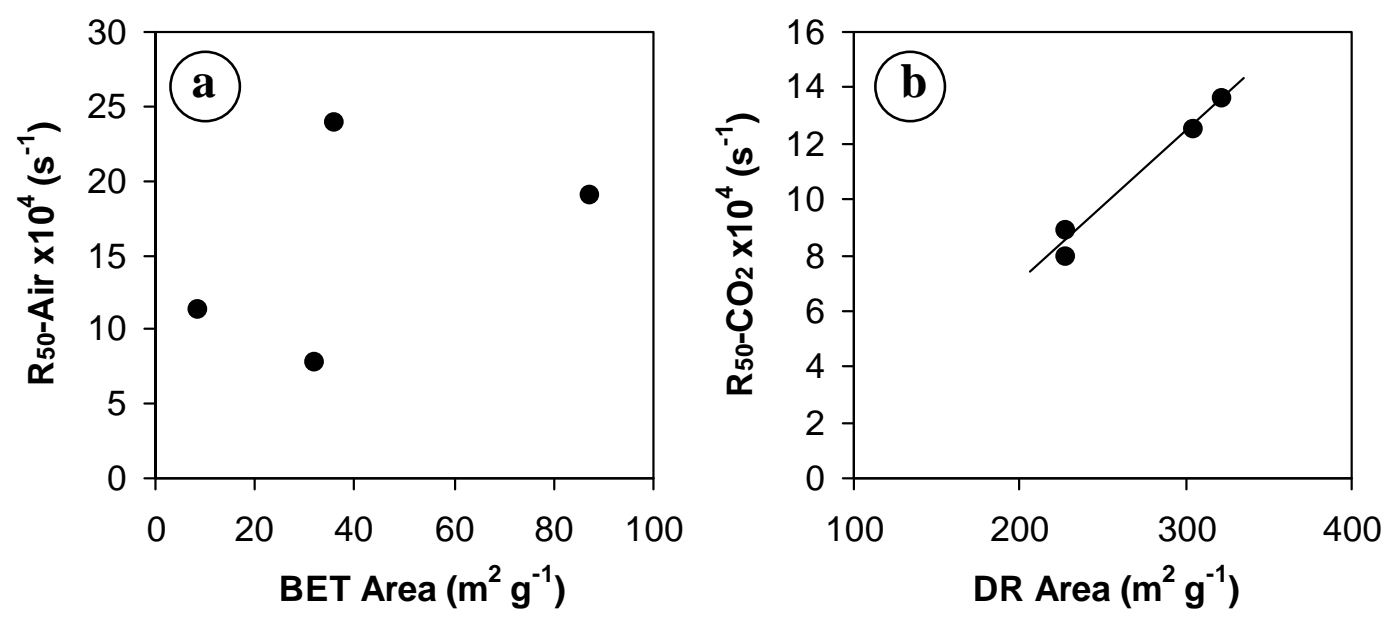

Figure 7. Relationship between: (a) BET surface areas from $\mathrm{N}_{2}$ adsorption isotherms and reactivity at $50 \%$ of burn-off in air $\left(500{ }^{\circ} \mathrm{C}\right)$; (b) surface areas from $\mathrm{CO}_{2}$ adsorption isotherms and reactivity at $50 \%$ of burn-off in $\mathrm{CO}_{2}\left(1000{ }^{\circ} \mathrm{C}\right)$. 

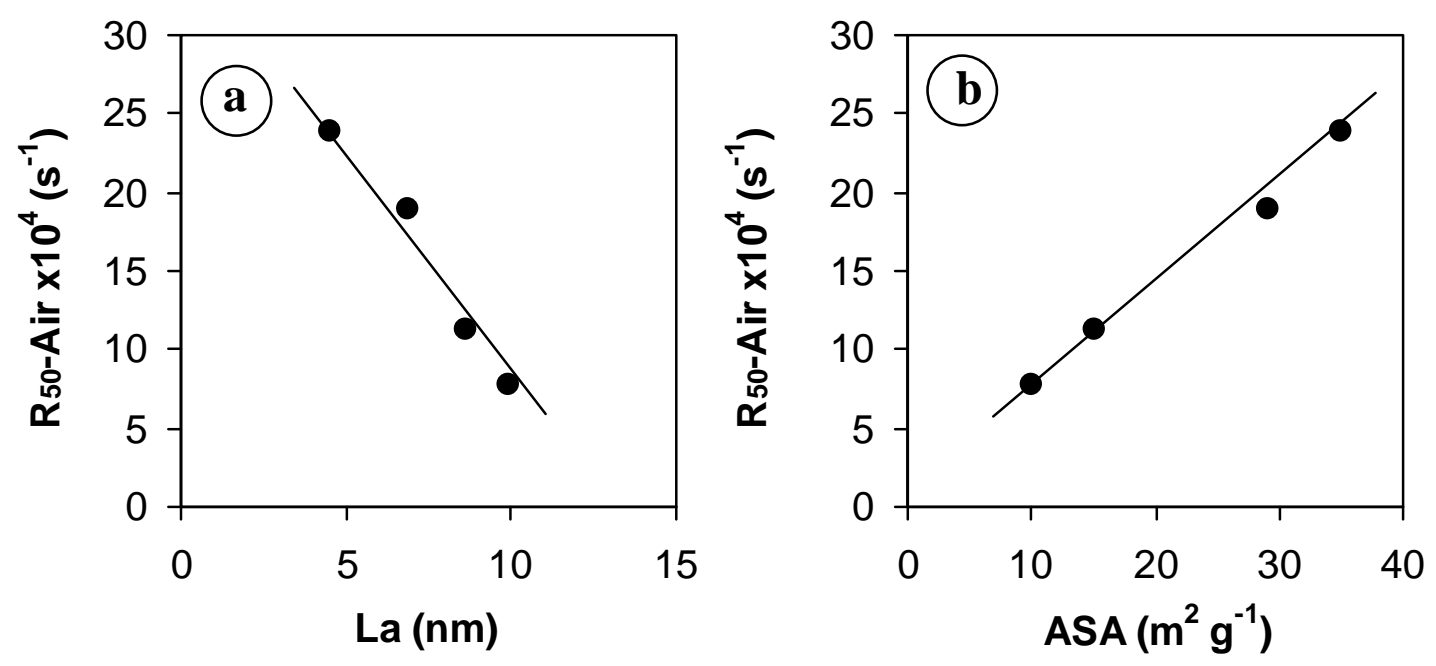

Figure 8. Relationship between: (a) the crystallographic parameter, $L a$, and reactivity at $50 \%$ of burn-off in air $\left(500^{\circ} \mathrm{C}\right)$; (b) active surface area values and reactivity at $50 \%$ of burn-off in air $\left(500^{\circ} \mathrm{C}\right)$. 